đánh giá sau 12 tháng cho thây nhóm bệnh nhân thiếu hụt hormon hoàn toàn có tốc độ tắng chiều cao và tăng SDS chiều cao tốt hơn so với nhóm thiếu hự 1 phần (tăng chiều cao: $10,1 \pm 2,8 \mathrm{~cm}$ với $8,4 \pm 1,9 \mathrm{~cm}, \mathrm{p}<0,001$; tốc độ tăng trưởng chiều cao theo SD: $0,97 \pm 0,65 \mathrm{SD}$ và̀ $0,62 \pm 0,42 \mathrm{SD}, \mathrm{p}=0,001)[8]$.

\section{KẾT LUÂ̂N}

Tuổi bắt đầu điều trị, tuổi xương thời điểm bắt đầu điều trị và nồng độ $\mathrm{GH}$ đỉnh trong test kích thích có liên quan tới kết quả điều trị. Điều tri càng sớm, tuổi xương thời điểm bắt đầu điều điều trị và nồng độ $\mathrm{GH}$ đỉnh càng thấp, tốc độ tăng trưởng chiều cao trong năm đầu càng cao.

\section{TÀI LIÊU THAM KHẢO}

1. Dattani M. and Preece M. (2004). Growth hormone deficiency and related disorders: insights into causation, diagnosis, and treatment. Lancet Lond Engl, 363(9425), 1977-1987.

2. Takeda A., Cooper K., Bird A. et al. (2010). Recombinant human growth hormone for the treatment of growth disorders in children: a systematic review and economic evaluation. Health Technol Assess Winch Engl, 14(42), 1-209, iii-iv.

3. Gharib H., Cook D.M., Saenger P.H., et al. (2003). American Association of Clinical Endocrinologists medical guidelines for clinical practice for growth hormone use in adults and children--2003 update. Endocr Pract Off J Am Coll Endocrinol Am Assoc Clin Endocrinol, 9(1), 64-76.

4. Grimberg A., DiVall S.A., Polychronakos $C_{\text {, }}$ et al . (2016). Guidelines for Growth Hormone and Insulin-Like Growth Factor-I Treatment in Children and Adolescents: Growth Hormone Deficiency, Idiopathic Short Stature, and Primary Insulin-Like Growth Factor-I Deficiency. Horm Res Paediatr, 86(6), 361-397.

5. Polak M., Blair J., Kotnik P, et al. (2017) Early growth hormone treatment start in childhood growth hormone deficiency improves near adult

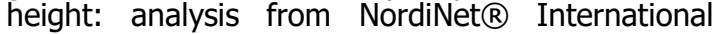
Outcome Study. Eur J Endocrinol, 177(5), 421-429.

6. Kang MJ., Kim EY., Shim YS., et al. (2019). Factors affecting bone age maturation during 3 years of growth hormone treatment in patients with idiopathic growth hormone deficiency and idiopathic short stature: Analysis of data from the LG growth study. Medicine (Baltimore), 98(14), $962-972$.

7. Kaplan S.L., Abrams C.A., Bell J.J, et al. (1968). Growth and growth hormone. I. Changes in serum level of growth hormone following hypoglycemia in 134 children with growth retardation. Pediatr Res, 2(1), 43-63.

8. Straetemans S., Thomas M., Craen $M$, et al. (2018). Poor growth response during the first year of growth hormone treatment in short prepubertal children with growth hormone deficiency and born small for gestational age: a comparison of different criteria. Int J Pediatr Endocrinol, 2018, 9 - 17.

\title{
HIÊUU QUẢ ÁP DƯNG THỬ NGHIỆM Bộ CÔNG CỤ GIÁM SÁT CHỦ ĐộNG CHẤT THẢI Y TẾ TẠI BẾNH VIỂN ĐA KHOA KHU VỰC PHÚC YÊN VÀ BỆNH VIÊ̂N ĐA KHOA THANH HÓA NĂM 2017
}

\section{Đàm Thương Thương ${ }^{1}$, Nguyễn Thanh Hà ${ }^{2}$ Trần Văn Tuấn ${ }^{3}$}

\section{TÓM TẮT}

Mục tiêu: Đánh giá được hiệu quả áp dung bô công cụ giám sát chủ động chất thải y tễ đối với công tác phẩn loại, thu gom, vận chuyển chất thải rắn tại BVĐK khu vực Phúc Yên và BVĐK tỉnh Thanh Hóa, năm 20217. Phương pháp: Nghiên cứu can thiệp đánh giá trước sau không có nhóm đối chứng, tại 33 khoa của 2 bệnh viện nghiên cứu. Kết quả: Tỷ lệ đạt các tiêu chí đánh giá về dụng cụ, thiết bị lưu chứa chất thải y tế, phân loại, thu gom và vận chuyển chất thải y tế theo từng ngày đều tăng với đa số các tiêu

\footnotetext{
${ }^{1}$ Viện Sức khỏe nghề nghiệp và môi trường-BYT ${ }^{2}$ Cưc Quản lý Môi trường Ỳ tế-BYT

${ }^{3}$ Học viện Quân Y.

Chịu trách nhiệm chính: Đàm Thương Thương

Email: damthuongthuong.nioeh@gmail.com

Ngày nhận bài: 21.12.2020

Ngày phản biện khoa học: 22.01.2021

Ngày duyệt bài: 2.2 .2021
}

chí đạt trên $90 \%$ sau 4 tuân thử nghiêm. Kết luân: Bộ công cụ giám sát chủ động chất thải y tế có hiệu quả trong công tác phân loại, thu gom và vận chuyển chất thải y tế tai hai bệnh viện được thử nghiệm.

Tư khoá: chất thải y tế, giám sát chủ động, quản lý môi trường y tế

\section{SUMMARY}

\section{EFECTIVE OF APPLICATION OF PROACTIVE MONITORING TOOLS FOR MEDICAL WASTE AT PHUC YEN GENERAL HOSPITAL AND} THANH HOA GENERAL HOSPTAL IN 2017

Objectives: To evaluate on the effectiveness of applying proactive environmental monitoring tools for medical solid waste sorting, collection and transportation at Phuc Yen regional general hospital and Thanh Hoa general hospital in 2017. Methods: Intervention study, evaluated before and after intervention without a control group, at 33 hospital wards of two hospital. Results: The result show that the rate of achieving the criteria for evaluation of 
medical waste storage devices and equipment, classification, collection, and transportation of medical waste by day be increased, the majority of the criteria reaching over $90 \%$ after 4 weeks of trial application of proactive monitoring tools. Conclusion: The proactive monitoring tools for medical waste were effective in increasing the rate of achieving the evaluation criteria in the classification, collection, and transportation of medical waste of two hospitals where were applied.

Keywords: medical waste, proactive monitoring, medical environment management

\section{I. ĐĂT VẤN ĐỀ}

Theo Tổ chức $Y$ tế Thế giới, quản lý tốt chất thải y tế (CTYT) góp phần giảm thiểu nguy cơ gây hại cho sức khoẻ con người và môi trường, là giảm chi phí trong quản lý, xử lý CTYT [2].

Hiện nay, tại các bệnh viện đã thực hiện việc giám sát phát sinh CTYT thông qua các đơn vị quan trắc môi trường (QTMT) có đủ chức năng theo định kỳ hàng năm. Để chủ động bảo vệ môi trường tại các bệnh viện tốt hơn, cần phải có các số liệu quan trắc CTYT thường xuyên và được cập nhật liên tục, bệnh viện phải có vai trò chủ động trong hoạt động bảo vệ môi trường. Một giải pháp được đưa ra là các bệnh viện có thể chủ động giám sát theo các chỉ tiêu QTMT để có thể chủ động có những đề xuất giải pháp kịp thời, phù hợp nhằm quản lý tốt CTYT. Bài báo trình bày kết quả nghiên cứu áp dụng thử nghiệm bộ công cụ giám sát chủ động chất thải y tế trong công tác phân loại, thu gom, vận chuyển chất thải rắn y tế tại bệnh viện đa khoa Phúc Yên và bênh viện đa khao Thanh Hóa, năm 2017, góp phần cung cấp bằng chứng khoa học cho các nhà hoạch định chính sách, các nhà quản lý y tế ra quyết định trong việc triển khai áp dụng bộ công cụ giám sát chủ động chất thải y tế tại các bệnh viện ở Việt Nam.

\section{II. ĐỐI TƯợNG VÀ PHƯƠNG PHÁP NGHIÊN CỨU}

2.1. Đối tượng nghiên cứu. Hồ sơ, sổ sách, báo cáo theo dõi về công tác phân loại, thu gom và vận chuyển chất thải rắn y tế năm 2017 của Bệnh viện đa khoa khu vực Phúc Yên và Bệnh viện đa khoa Thanh Hóa.

2.2. Thời gian và địa điểm nghiên cứu. Nghiên cứu tiến hành năm 2017 tại BVĐK khu vực Phúc Yên, và BVĐK tỉnh Thanh Hóa.

2.3. Thiết kế nghiên cứu. Nghiên cứu can thiệp, đánh giá trước sau không có nhóm đối chứng.

2.4. Cỡ mẫu và phương pháp chọn mẫu nghiên cứu. Chọn toàn bộ 33 khoa chuyên môn của BVĐK khu vực Phúc Yên và 35 khoa của BVĐK tỉnh Thanh Hóa tham gia vào giai đoan thử nghiệm và đánh giá hiệu quả sử dụng bộ công cụ giám sát môi trường chủ động.

2.5. Biến số chính. Hiệu quả chất thải rắn y tế phát sinh sau can thiệp so với trước can thiệp (kg/ngày); đạt tiêu chí đánh giá về dụng cụ, thiết bị lưu trữ chất thải y tễ sau can thiệp so với trước can thiệp; đạt tiêu chí đánh giá về phân loại chất thải y tế theo từng ngày sau can thiệp so với trước can thiệp; đạt tiêu chí đánh giá về thu gom chất thải y tế sau can thiệp so với trước can thiệp; đạt tiêu chí đánh giá về các thiết bị và phương tiện làm sạch và khử trùng vận chuyển chất thải $y$ tế theo từng ngày sau can thiệp so với trước can thiệp; đạt tiêu chí đánh giá về vận chuyển chất thải $\mathrm{y}$ tể theo từng ngày sau can thiệp so với trước can thiệp.

\subsection{Phương pháp thu thâp số liêuu \\ Các bước tiến hành can thiệp:}

Bước 1: Khảo sát và thống nhất kế hoạch triển khai thử nghiệm mô hình giám sát chủ động chất thải y tế tại hai bệnh viện được chọn

Bước 2: Xây dựng bộ công cụ giám sát chủ động chất thải y tế: là phiếu kiểm soát môi trường tại các khoa phòng trong bệnh viện với các nội dung như: Kiểm kê lượng CTYT phát sinh; Giám sát công tác phân loaii, thu gom, vân chuyển chất thải rắn y tế tại bệnh viện trong thời gian quy định theo các tiêu chí của hoạt động QTMT.

Bước 3: Tập huấn sử dụng bộ công cụ giám sát chủ động chất thải y tế. Đối tượng tham gia tập huấn là điều dưỡng trưởng và nhân viên kiểm soát nhiễm khuẩn tại các khoa.

Bước 4: Tiến hành thử nghiệm mô hình. Thời gian thử nghiệm trong 4 tuân liên tiếp $(T 1, T 2$, T3, T4). Tổ chức hoạt động giám sát môi trường 3 lần/tuân vào các ngày thứ hai, thứ tư, thứ sáu.

Bước 5: Đánh giá hiệu quả sau thử nghiệm mô hình sau 4 tuần thử nghiệm mô hình giám sát chủ động chất thải y tế tại bệnh viện.

Kỹ thuật thu thập số liệu:

Cân định lượng CTRYT tại các Khoa/Phòng của bệnh viện theo các thời điểm khác nhau trong ngày (sáng: 8:00 - 9:00, trưa: 13h00 $14 \mathrm{~h} 00$, chiều: $17 \mathrm{~h} 00$ - 18h00), sau đó lấy giá trị trung bình của các lần cân định lượng. Cân định lượng CTRYT 3 lần/tuần (thứ hai, thứ tư, thứ sáu) và kéo dài trong 4 tuần liên tiếp.

Cán bộ Khoa Kiểm soát nhiễm khuẩn tại bệnh viện sử dụng bộ công cụ giám sát chủ động của nghiên cứu và quan sát trực tiếp và ghi chép số liệu, thông tin về quá trình thực hiện phân loại, thu gom và vận chuyển CTRYT. Quá trình này được thực hiện 3 lần/tuần (thứ hai, thứ tư, thứ sáu), kéo dài trong 4 tuần liên tiếp. 
2.6. Phương pháp xử lý số liệu. Số liệu được nhập vào phần mềm Microsoft Excel 2007 và phân tích phần mềm SPSS 20.0.

2.7. Đạo đức nghiên cứu. Đề cương nghiên cứu được thông qua bởi Hội đồng đạo đức của Học viện Quân y. Nghiên cứu đảm bảo không vi phạm các yêu câu về y đức trong nghiên cứu.

\section{KẾT QUẢ NGHIÊN CỨU}

Bảng 1. Khôi lượng chất thải rắn y tế phát sinh tại hai bệnh viện tham gia nghiên cứu (kg/ngày/khoa)

\begin{tabular}{|c|c|c|c|}
\hline Loại CTRYT & $\begin{array}{c}\text { Trước can thiệp } \\
\text { Trung vị }\left(\mathbf{Q}_{1}-\mathbf{Q}_{3}\right) \\
\bar{X} \pm S D\end{array}$ & $\begin{array}{c}\text { Sau can thiệp } \\
\text { Trung vị }\left(\mathbf{Q}_{1}-\mathbf{Q}_{3}\right) \\
\bar{X} \pm S D\end{array}$ & HQCT \\
\hline \multicolumn{4}{|c|}{ Bệnh viện đa khoa khu vực Phúc Yên (n=33 Khoa) } \\
\hline CTYT sắc nhọn & $\begin{array}{c}0,53(0,27-1,27) \\
0,90 \pm 0,92\end{array}$ & $\begin{array}{c}0,50(0,21-1,08) \\
0,78 \pm 0,86\end{array}$ & 15,38 \\
\hline CTYT lây nhiễm không sắc nhọn & $\begin{array}{c}3,38(1,57-8,33) \\
5,33 \pm 4,70\end{array}$ & $\begin{array}{c}2,98(1,70-7,55) \\
4,82 \pm 4,29\end{array}$ & 10,58 \\
\hline CTYT tái chế & $\begin{array}{c}1,28(0,28-2,07) \\
1,62 \pm 2,23\end{array}$ & $\begin{array}{c}1,37(0,57-2,15) \\
1,99 \pm 2,19\end{array}$ & 18,59 \\
\hline CTYT không tái chế & $\begin{array}{c}15,50(9,50-19,62) \\
15,76 \pm 7,00\end{array}$ & $\begin{array}{c}14,23(8,62-18,03) \\
14,03 \pm 6,06\end{array}$ & 12,33 \\
\hline Tổng & $\begin{array}{c}23,37(11,97-30,60) \\
23,67 \pm 12,09\end{array}$ & $\begin{array}{c}21,77(11,28-29,14) \\
21,29 \pm 10,91\end{array}$ & 11,18 \\
\hline \multicolumn{4}{|c|}{ Bệnh viện đa khoa khu vực Thanh Hóa (n=35 Khoa) } \\
\hline CTYT sắc nhọn & $\begin{array}{c}0,46(0,20-0,90) \\
0,65 \pm 0,62\end{array}$ & $\begin{array}{c}0,46(0,20-1,35) \\
0,74 \pm 0,64\end{array}$ & 12,16 \\
\hline CTYT lây nhiễm không sắc nhọn & $\begin{array}{c}2,56(1,07-4,15) \\
4,39 \pm 7,39\end{array}$ & $\begin{array}{c}4,67(3,28-5,45) \\
5,48 \pm 6,12\end{array}$ & 19,89 \\
\hline CTYT tái chế & $\begin{array}{c}2,32(1,47-3,60) \\
2,97 \pm 2,26\end{array}$ & $\begin{array}{c}11,43(10,57-13,33) \\
12,84 \pm 3,99\end{array}$ & 76,87 \\
\hline CTYT không tái chế & $\begin{array}{c}48,87(33,57-74,63) \\
54,21 \pm 29,59\end{array}$ & $\begin{array}{c}39,00(24,57-59,60) \\
43,41 \pm 25,40\end{array}$ & 24,88 \\
\hline Tổng & $\begin{array}{c}49,36(37,97-81,03) \\
59,23 \pm 29,71\end{array}$ & $\begin{array}{c}54,49(40,68-78,28) \\
61,36 \pm 25,25\end{array}$ & 3,47 \\
\hline
\end{tabular}

Khối lượng CTRYT phát sinh trung bình ngày đã giảm sau 4 tuần thực hiện mô hình giám sát chủ động. Tuy nhiên, lượng CTYT tái chế tăng với HQCT đạt 76,87\%; CTYT không tái chế giảm với HQCT đạt $24,88 \%$.

Bảng 2. Tỷ lệ đạt tiêu chí đánh giá về dụng cụ, thiêt bị lưu trữ chât thải y tế theo ngày (\%)

\begin{tabular}{|c|c|c|c|c|c|c|c|}
\hline \multirow{2}{*}{\multicolumn{2}{|c|}{ Tiêu chí đánh giá }} & \multicolumn{3}{|c|}{$\begin{array}{l}\text { Bệnh viện đa khoa khu vực } \\
\text { Phúc Yên (33 Khoa) }\end{array}$} & \multicolumn{3}{|c|}{$\begin{array}{l}\text { Bệnh viện đa khoa tỉnh } \\
\text { Thanh Hoá (35 Khoa) }\end{array}$} \\
\hline & & Trước CT & Sau CT & HQCT & Trước CT & Sau CT & HQCT \\
\hline \multirow{3}{*}{$\begin{array}{c}\text { Hộp chứa/đựng chất thải lây } \\
\text { nhiễm sắc nhọn đúng quy } \\
\text { định }\end{array}$} & Thứ 2 & 71,9 & 87,9 & 18,20 & 68,6 & 100 & 31,40 \\
\hline & Thứ 4 & 37,5 & 87,9 & 47,34 & 25,7 & 100 & 74,30 \\
\hline & Thứ 6 & 25,0 & 87,9 & 71,55 & 17,1 & 96,9 & 82,35 \\
\hline \multirow{3}{*}{$\begin{array}{l}\text { Túi/thùng chứa/đựng chất } \\
\text { thải lây nhiễm không sắc } \\
\text { nhọn đúng quy định }\end{array}$} & Thứ 2 & 84,8 & 93,9 & 9,69 & 68,6 & 94,3 & 27,25 \\
\hline & Thứ 4 & 93,8 & 93,9 & 0,11 & 62,9 & 100 & 37,10 \\
\hline & Thứ 6 & 84,4 & 93,9 & 10,12 & 11,4 & 100 & 88,60 \\
\hline \multirow{3}{*}{$\begin{array}{c}\text { Túi/thùng chứa/đựng chất } \\
\text { thải nguy hại khồng lây } \\
\text { nhiếm đúng quy định }\end{array}$} & Thứ 2 & 53,1 & 93,9 & 43,45 & 2,9 & 100 & 97,10 \\
\hline & Thứ 4 & 62,5 & 93,9 & 33,44 & 0,0 & 100 & 100,00 \\
\hline & Thứ 6 & 18,8 & 93,9 & 79,98 & 0,0 & 100 & 100,00 \\
\hline \multirow{3}{*}{$\begin{array}{l}\text { Túi/thùng chứa/đựng CTYT } \\
\text { thông thường đúng quy định }\end{array}$} & Thứ 2 & 84,8 & 100 & 15,20 & 100 & 100 & 0 \\
\hline & Thứ 4 & 97,0 & 100 & 3,00 & 97,1 & 100 & 2,90 \\
\hline & Thứ 6 & 90,9 & 100 & 9,10 & 97,1 & 100 & 2,90 \\
\hline Túi/thùng chứa/đựng chất & Thứ 2 & 54,5 & 100 & 45,50 & 2,9 & 100 & 97,10 \\
\hline
\end{tabular}


VIETNAM MEDICAL JOURNAL N¹\&2 - FEBRUARY - 2021

\begin{tabular}{|c|c|c|c|c|c|c|c|}
\hline thải được phép thu gom, & Thứ 4 & 27,3 & 100 & 72,70 & 0,0 & 100 & 100,00 \\
\cline { 2 - 8 } tái chể đúng quy định & Thứ 6 & 24,2 & 100 & 75,80 & 0,0 & 100 & 100,00 \\
\hline \multirow{2}{*}{$\begin{array}{c}\text { Túi//thùng chứa/đựng } \\
\text { sạch có sắn để thay thế }\end{array}$} & Thứ 2 & 84,8 & 100 & 15,20 & 68,6 & 97,1 & 29,35 \\
\cline { 2 - 8 } & Thứ 4 & 87,9 & 100 & 12,10 & 37,1 & 97,1 & 61,79 \\
\cline { 2 - 8 } & Thứ 6 & 27,3 & 100 & 72,70 & 20,0 & 94,3 & 78,79 \\
\hline
\end{tabular}

Bênh viện đa khoa khu vực Phúc Yên, sự cải thiên này có tiêu chí đạt HQCT tới $75 \%$ với đa số các ngày được giám sát. Bệnh viện đa khoa Thanh Hoá, tỷ lệ đạt các chỉ tiêu giám sát về dụng cụ, thiết bị lưu chứa CTYT trong Tuần 0 dao động mạnh từ $0 \%-97,1 \%$, đã tăng lên đáng kể tại tuần 4 sau thử nghiệm mô hình $(58,1 \%-100 \%)$. Sự cải thiện này có tiêu chí đạt HQCT $100 \%$.

Bảng 3. Tỷ lệ đạt tiêu chí đánh giá về phân loại chât thải y tê theo ngày (\%)

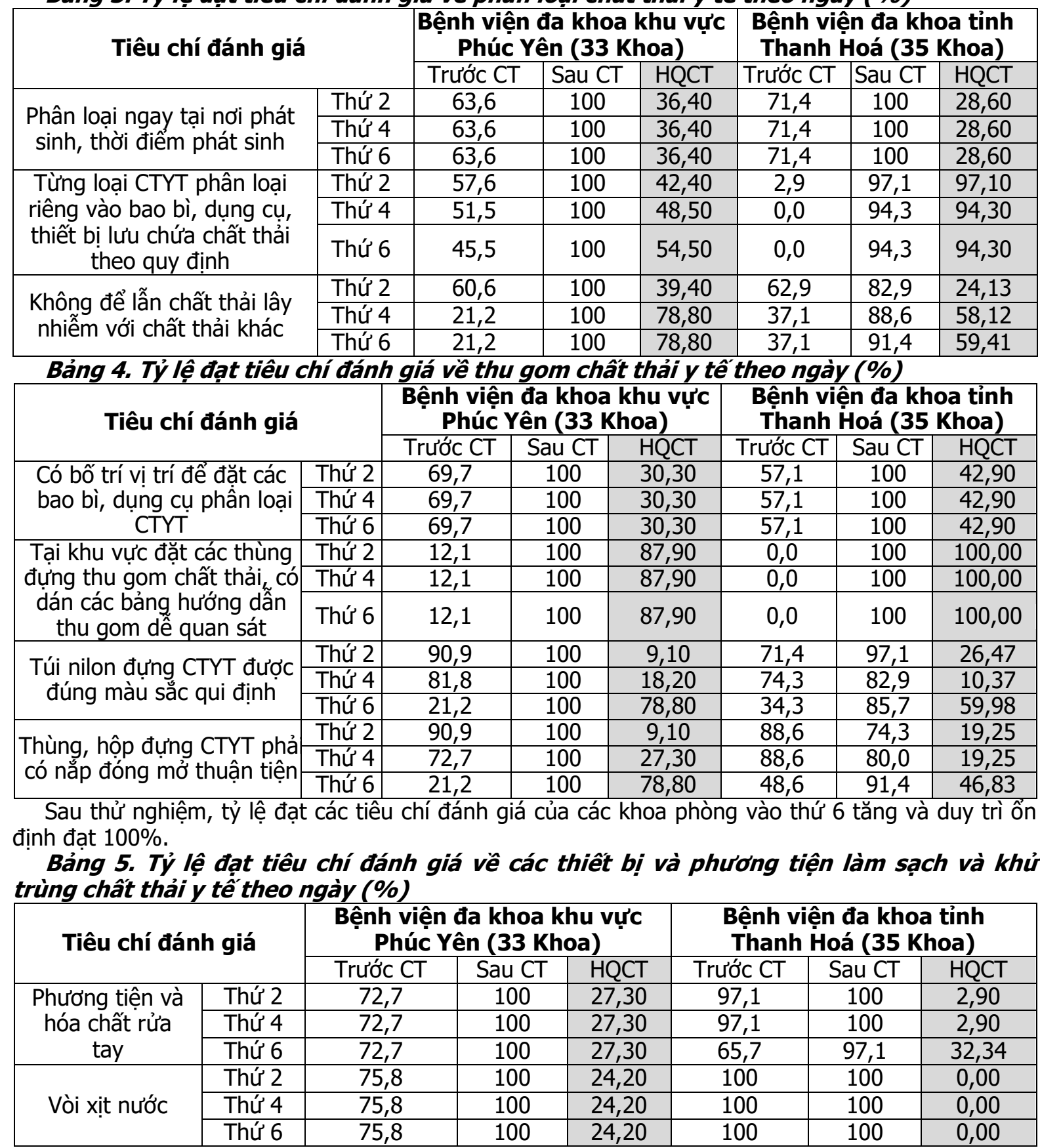




\begin{tabular}{|c|c|c|c|c|c|c|c|c|}
\hline \multirow{3}{*}{$\begin{array}{c}\text { Dụng cụ lau, cọ } \\
\text { sàn }\end{array}$} & Thứ 2 & 66,7 & 97,0 & \multicolumn{2}{|c|}{31,23} & \multicolumn{2}{|r|}{100} & 68,60 \\
\hline & Thứ 4 & 66,7 & 97,0 & 31,23 & \multicolumn{2}{|c|}{37,1} & 100 & 62,90 \\
\hline & Thứ 6 & 66,7 & \multirow{2}{*}{$\begin{array}{l}97,0 \\
970\end{array}$} & 31,23 & \multicolumn{2}{|c|}{65,7} & 100 & 34,30 \\
\hline \multirow{3}{*}{$\begin{array}{l}\text { Dụng cụ lau, cọ } \\
\text { thùng đựng } \\
\text { chất thải }\end{array}$} & Thứ 2 & 66,7 & & \multirow{2}{*}{$\frac{31,23}{71,86}$} & \multicolumn{2}{|c|}{0,0} & 100 & 100,00 \\
\hline & Thứ 4 & 27,3 & $\begin{array}{l}97,0 \\
97,0\end{array}$ & & \multirow{2}{*}{\multicolumn{2}{|c|}{2,9}} & 97,1 & 97,01 \\
\hline & Thứ 6 & 21,2 & 97,0 & 78,14 & & & 97,1 & 97,10 \\
\hline \multirow{3}{*}{$\begin{array}{l}\text { Hóa chất làm } \\
\text { sạch và khử } \\
\text { trùng }\end{array}$} & Thứ 2 & 87,9 & 97,0 & 9,38 & \multicolumn{2}{|c|}{54,3} & 100 & 45,70 \\
\hline & Thứ 4 & 87,9 & 97 & 9,3 & & 1,4 & 100 & 68,60 \\
\hline & Thứ 6 & 30,3 & 97 & 68, & &, 0 & 97,1 & 79,40 \\
\hline Bảng 6. Tý & t tiêu & tánh & ề vận & yến c & thải ] & $t e ̂$ & ngày & \\
\hline Ti & án & & $\begin{array}{r}\text { Bệnh việ } \\
\text { Phúc }\end{array}$ & $\begin{array}{l}\text { khoa } \\
\text { (33 }\end{array}$ & ) vực & $\begin{array}{l}\text { Bệnh vi } \\
\text { Thanh }\end{array}$ & iện đa & $\begin{array}{l}\text { oa tỉnh } \\
\text { Khoa) }\end{array}$ \\
\hline & & & Trước CT & Sau CT & HQCT & Trước CT & Sau CT & $\mathrm{HQCT}$ \\
\hline Không C & g để lẫn & Thứ 2 & & 97,0 & & & 91,4 & 62,47 \\
\hline & CTYT & Thứ 4 & & 0 & & & 94 & 45,49 \\
\hline & & Thứ 6 & & 97,0 & 78,14 & 40 & 94,3 & 57,58 \\
\hline Việc vận chuyển & YT được & Thứ 2 & 7 & 100 & 27,30 & 97,1 & 100 & 2,90 \\
\hline thực hiện & gian quy & Thứ 4 & 69,7 & 100 & 30,30 & 97,1 & 100 & 2,90 \\
\hline & & Thứ 6 & 69,7 & 100 & 30,30 & 97,1 & 100 & 2,90 \\
\hline liệc vận chuyể & hông & Thứ 2 & & 10 & 45,50 & 28 & 88 & 67,72 \\
\hline làm ró & TYT ra & Thứ 4 & & 100 & 66,70 & 42 & 80,0 & 46,38 \\
\hline & & Thứ 6 & 30,3 & 100 & 69,70 & 57,1 & 85,7 & 33,37 \\
\hline
\end{tabular}

Tỷ lệ đạt các tiêu chí đánh giá về dụng cụ, thiết bị lưu chứa chất thải y tế, phân loại, thu gom và vận chuyển chất thải y tế theo từng ngày đều tăng với đa số các tiêu chí đạt trên $90 \%$ sau 4 tuần thử nghiệm.

\section{BÀN LUÂ̂N}

Kết quả đánh giá tại Bệnh viện đa khoa khu vực Phúc Yên trong nghiển cứu của chúng tôi cho thấy, nhìn chung khối lượng CTRYT phát sinh $(\mathrm{kg} / \mathrm{ngày})$ có xu hướng giảm sau 4 tuần thử nghiệm mô hình giám sát chủ động môi trường bệnh viện, còn $21,29 \pm 10,91 \mathrm{~kg} / \mathrm{ngày}$, thấp hơn so với Bệnh viện nhiệt đới Trung ương, trung bình mỗi ngày có khoảng $30 \mathrm{~kg}$ CTRYT lây nhiễm sắc nhọn và $100 \mathrm{~kg}$ chất thải không sắc nhọn, phát sinh ở hai cơ sở của bệnh viện [3]. Mặc dù chưa có sự giảm khác biệt có ý nghĩa thống kê giữa tuần trước thử nghiệm và sau 4 tuần thử nghiệm nhưng đây cũng là dấu hiệu cải thiện tốt về thực trang phát sinh chất thải rắn tại bênh viện này. Đặc biệt, lượng CTRYT tái chế tại bệnh viện có xu hướng tăng lên, cho thấy hoạt động phân loại chất thải rẳn tại bệnh viện được cải thiện rõ rệt.

Trong khi đó, đối với bệnh viện đa khoa Thanh Hoá cho kết quả ngược lại, tổng lượng chất thải phát sinh của tuần trước thử nghiêm thấp hơn so với tuần 4 sau thử nghiệm. Có thể lý giải cho sự tăng này là do sự gia tăng về số lượng bệnh nhân đến khám, chăm sóc, điều trị, và sử dụng các dịch vụ y tế khác tại bệnh viện trong thời gian thử nghiệm mô hình.

Kết quả nghiên cứu của chúng tôi cho thấy ở cả hai bênh viên đều có sự cải thiên tốt về hoat động phân loại và thu gom CTRYT. Thực tế cho thấy, việc thực hiện khâu phân loại chất thải rắn tại bệnh viện cần có sự tham gia phối hợp tích cực của tất cả mọi người, từ ban lãnh đạo bệnh viện, các trưởng phó khoa và nhân viên tại các khoa/phòng, nhân viên trực tiếp thực hiện quá trình phân loại chất thải rắn.

Theo Quy định, chất thải được vận chuyển từ nơi phát sinh tới khu vực lưu giữ tập trung của bệnh viên bằng xe chuyền dụng đúng quy định ít nhất mối ngày một lần. Nhân viên vận chuyển phải mặc thiết bị bảo hộ lao động như: quần áo bảo hộ, đội mũ, đeo khẩu trang và găng tay trong suốt quá trình vận chuyển. Không được xách túi chất thải trong quá trình vận chuyển. Xe vận chuyển chất thải phải được co rửa, làm sach ngay sau mỗi lần thu gom. Ngoài ra, bệnh viện cần phải quy định tuyến/đường vận chuyển chất thải và thời điểm vận chuyển nhằm giảm thiểu tối đa ảnh hưởng của hoạt động thu gom vận chuyển đến hoạt động khám, chứa bệnh tại bệnh viện [4]. Trong nghiên cứu của chúng tối tỷ lệ các khoa đạt về các chỉ tiêu quan trắc liên quan đến dụng cụ, thiết bị lưu chứa CTYT bao gồm: hộp chứa/đựng chất thải lây nhiễm sắc nhọn, túi//thùng chứa/đựng chất thải lây nhiễm khồng sắc nhọn, chất thải nguy hại không lây 
nhiễm, CTYT thông thường,.. và quá trình vân chuyển CTYT được cải thiện rõ rệt sau 4 tuần thử nghiệm.

\section{KẾT LUÂ̂N VÀ KIẾN NGH!}

Kết luận: Bộ công cụ giám sát chủ động chất thải y tế có hiệu quả trong cải thiện tỷ lệ đạt các tiêu chí đánh giá trong công tác phân loại, thu gom và vận chuyển chất thải y tế tại bệnh viện đa khoa khu vực Phúc Yên và bệnh viện đa khoa tỉnh Thanh Hóa. Tỷ lệ đạt các tiêu chí đánh giá về dụng cụ, thiết bị lưu chứa chất thải y tế, phân loại, thu gom và vận chuyển chất thải y tế tăng với đa số các tiêu chí đạt trên $90 \%$ ở tuần thứ 4 sau thử nghiệm bộ công cụ giám sát chủ động chất thải y tế.

Kiến nghị: Cần tiếp tục duy trì áp dụng mô hình và có chỉnh sửa, điều chỉnh cho phù thực tiễn hoạt động khám chữa bệnh và mức độ phát thải của bệnh viện để có thể áp dụng rộng rãi hơn.

\section{TÀI LIÊU THAM KHẢO}

1. Bộ $Y$ tế. Điểm tin y tế ngày $15 / 12 / 2017$. Tại: httips://www.moh.gov.vn/diem-tin-y-te//asset_publisher/ sqTagDPp4aRX/content/-iem-tiny-te-ngay-15-12-2017?inheritRedirect=false.

2. Chartier $\mathbf{Y}$ et al. Safe management of wastes from health-care activities. World Health Organization. 2014.

3. Tạp chí môi trường. Các bệnh viện thực hiện phân loại rác thải tai nguồn 2019. Tại: http://tapchimoitruong.vn/pages/article.aspx?item $=\mathrm{C} \% \mathrm{C} 3 \% \mathrm{~A} 1 \mathrm{c}-\mathrm{b} \% \mathrm{E} 1 \% \mathrm{BB} \% 87 \mathrm{nh}-$ vi\%E1\%BB\% 87 n-th\%E1\%BB\%B1chi\%E1\%BB\%87n-ph\%C3\%A2n-lo\%E1\%BA\%A1ir\%C3\%A1c-th\%E1\%BA\%A3i-t\%E1\%BA\%A1ingu $\%$ E1\%BB\%93n-50659.

4. Bộ Y tế. Sổ tay hướng dẩn quản lý chất thải y tế trong bệnh viện. Nhà xuất bản Y học Hà Nội. 2015.

\section{TĂNG HUYẾT ÁP ÁO CHOÀNG TRẮNG VÀ TĂNG HUYẾT ÁP ẨN GIẤU Ở BÊ̂NH NHÂN ĐÁI THÁO ĐƯờNG TÍP 2: XUẤT Độ VÀ YẾU TỐ LIÊN QUAN}

TÓM TĂT

Mở đâu: Tăng huyết áp (THA) là bệnh lý đi kèm thường gặp nhất trên người bệnh đái tháo đường (ĐTĐ). Các thể THA như THA áo choàng trắng và THA ẩn giấu có tỉ lệ khá cao đối với người bệnh ĐTĐ, đặc biệt là ĐTÐ típ 2. Mục tiêu: Xác định tỉ lệ và các yểu tố liên quan của THA áo choàng trắng và THA ẩn giấu trên người bệnh đái tháo đường típ 2 . Đối tượng và phương pháp nghiên cứu: Nghiên cứu mô tả cắt ngang trên 306 người bệnh tại phòng khám Nội Tiết ngoai trú, Bệnh viên Nhân Dân Gia Đinh TP.Hồ Chí Minh. Kết quả: 24,5\% đối tượng có THA ẩn giấu, $30,1 \%$ có THA áo choàng trắng. Các yếu tố như đố tuổi, thời gian mắc ĐTĐ, tiền sử gia đinnh THA, ĐTĐ, hút thuốc lá, uống rượu bia, ăn măn và tâp thể duc có mối liên quan chung với các thể THA. Kết luận: Kết quả nghiên cứu nhắc lai việc ứng dung đo hưyết áp liên tục 24 giờ trong xác định các thể THA, góp phân phòng ngừa các biến cố bất lợi do THA gây ra trên người bệnh ĐTĐ típ 2.

Tư khóa: THA áo choàng trắng, THA ẩn giấu, ĐTĐ típ 2, yếu tố nguy cơ

\section{SUMMARY}

\footnotetext{
*Bệnh viện đa khoa tỉnh Bình Dương

**Đai hoc Y dước thành phố Hồ Chí Minh

Chịu trách nhiệm chính: Nguyễn Văn Lực

Email: nguyenvanlucphoto@gmail.com

Ngày nhận bài: 18.12.2020

Ngày phản biện khoa học: 22.01.2021

Ngày duyệt bài: 01.2.2021
}

\section{WHITE-COAT HYPERTENSION AND MASKED HYPERTENSION IN DIABETIC TYPE 2 PATIENTS: PREVALENCE AND THEIR RELATED FACTORS}

Introduction: Hypertension is the most common comorbidity of diabetes. White-coat and masked hypertension are high prevalence hypertension phenotypes, especially in type 2 diabetic patients. Objectives: To evaluate the prevalence and related factors of white-coat and masked hypertension in type 2 diabetic patients. Method: A cross-sectional study was conducted in 306 diabetic type 2 patients in Nhan Dan Gia Dinh hospital - Ho Chi Minh city. Results: The prevalence of white-coat and masked hypertension were $30.1 \%$ and $24.5 \%$, respectively. Aqe, family history of hypertension, diabetes, smoking, drinking, salt consuming, and physical activites were associated with hypertension phenotypes. Conclusion: Data remind us of application ambulatory blood pressure monitoring to identify hypertension phenotypes for prevention adverse events in type 2 diabeticsubjects.

Keyword: White-coat hypertension, masked hypertension, diabetes type 2 , related factors

\section{I. ĐĂT VẤN ĐỀ}

Tăng huyết áp (THA) và đái tháo đường (ĐTÐ) là hai bệnh lý mạn tính đang gia tăng với tốc độ nhanh chóng trên toàn cầu. Sự tác động cộng hợp giữa THA và ĐTĐ gây nhiều hệ quả nghiêm trọng đến hệ thống tim mạch. Bệnh nhân ĐTÐ kèm THA tắng nguy cơ tim mạch gấp 